\title{
Demens og nevropsykiatriske symptomer hos sykehjemspasienter i Nord-Trøndelag
}

Engelsk oversettelse på www.tidsskriftet.no

\begin{abstract}
Sammendrag
Bakgrunn. Tidligere studier har vist at det er høy forekomst av demens blant sykehjemspasienter. Vi har gjennomført en deskriptiv kartlegging av demens og nevropsykiatriske symptomer blant pasienter i sykehjem i NordTrøndelag.
\end{abstract}

Materiale og metode. 704 sykehjemspasienter ble inkludert og kartlagt med kartleggingsverktøyet Klinisk demensvurdering og Nevropsykiatrisk intervjuguide.

Resultater. Basert på kartleggingen hadde 575 pasienter ( $82 \%$ ) demens. Av disse hadde 430 pasienter (75\%) minst ett klinisk signifikant nevropsykiatrisk symptom i tillegg, hyppigst vrangforestillinger, apati og irritabilitet. De nevropsykiatriske symptomene kunne samles i fire kategorier: psykose, apati, affektive symptomer og agitasjon.

Fortolking. Funnene er sammenliknbare med funn fra tidligere studier av norske sykehjemspasienter. Den høye forekomsten av demens og nevropsykiatriske symptomer har betydning for klinisk praksis, drift og planlegging av sykehjem.

\section{Sverre Bergh}

sverre.bergh@sykehuset-innlandet.no

Alderspsykiatrisk forskningssenter

Sykehuset Innlandet

\section{Jostein Holmen}

HUNT forskningssenter

Institutt for samfunnsmedisin

Norges teknisk-naturvitenskapelige universitet

Ingvild Saltvedt

Avdeling for geriatri

St. Olavs hospital

og

Institutt for nevromedisin

Norges teknisk-naturvitenskapelige universitet

\section{Kristian Tambs}

Avdeling for psykisk helse

Nasjonalt folkehelseinstitutt

\section{Geir Selbæk}

Alderspsykiatrisk forskningssenter

Sykehuset Innlandet

og

Akershus universitetssykehus

Demens er et syndrom som omfatter kognitiv svikt, endring $i$ atferd og/eller sosial funksjon og svikt i dagliglivets funksjoner. Omtrent 70000 personer i Norge lider av demens (1). Hyppigst forekommende er Alzheimers sykdom, vaskulær demens, frontotemporallappsdemens, Parkinsons sykdom, demens med lewylegemer og alkoholutløst demens.

Mange med demens opplever angst, depresjon, hallusinasjoner, vrangforstillinger, aggresjon, avvikende motorisk atferd, apati eller endringer i appetitt og søvnmønster. Disse symptomene er samlet under betegnelsene nevropsykiatriske symptomer ved demens eller atferdsmessige- og psykologiske symptomer ved demens. Kognitiv svikt og nevropsykiatriske symptomer er en byrde for pasient, pårørende og pleiepersonell (2). Nevropsykiatriske symptomer kan føre til mer tvang (3) og økt bruk av psykofarmakologiske medikamenter (4). Både biologiske, psykososiale og miljømessige forhold har betydning for utviklingen av nevropsykiatriske symptomer (5).

Tidligere studier har vist at omtrent $80 \%$ av norske sykehjemspasienter har demens, og at rundt $70 \%$ av pasientene med demens har klinisk signifikante nevropsykiatriske symptomer $(6,7)$. Tilsvarende tall er rapportert fra Nederland og Storbritannia (8-10). Tidligere faktoranalyser har vist at nevropsykiatriske symptomer kan grupperes i fire kategorier: psykotiske symptomer, affektive symptomer, symptomer på agitasjon og symptomer på apati (11).

Nord-Trøndelag består av 23 kommuner en blanding av by- og landkommuner med kyst- og innlandsbosetning. Vi ønsket å kartlegge forekomsten av demens ved sykehjem i Nord-Trøndelag og beskrive forekomsten av nevropsykiatriske symptomer hos pasienter med demens. Vi ønsket også å identifisere subgrupper av nevropsykiatriske symptomer, dvs. symptomer som kan være relevante for å forstå årsakene til demens og som kan bidra til bedre behandling.

\section{Materiale og metode}

Alle pasientene ved samtlige 32 sykehjem i Nord-Trøndelag ble invitert til å delta i studien. Inklusjonskriteriet var at vedkommende hadde bodd på sykehjemmet i minst to uker. Av 979 aktuelle pasienter ble 259 ekskludert fordi pasienten selv eller pårørende sa nei $(n=197)$ eller pga. somatisk sykdom $(\mathrm{n}=24)$, død før datainnsamlingen startet $(\mathrm{n}=17)$, fordi pasienten var utskrevet fra sykehjemmet $(\mathrm{n}=1)$ eller av ukjent årsak $(\mathrm{n}=20)$. 16 av 720 inkluderte pasienter var ikke kartlagt med kartleggingsverktøyet Klinisk demensvurdering. Dermed inngikk 704 pasienter i studien.

\section{Datainnsamling}

Kartleggingen skjedde fra juni 2010 til mars 2011 og bygde på et standardisert intervju med pasienter og helsepersonell ved sykehjemmene. Ni prosjektsykepleiere med bred klinisk erfaring sto for datainnsamlingen. De fikk to dagers opplæring i bruk av kartleggingsskjemaet og generell informasjon om studien. Kartleggingen omfattet undersøkelse av nevropsykiatriske symptomer,

\section{Hovedbudskap}

- Ved bruk av et kartleggingsverktøy hadde rundt $80 \%$ av sykehjemspasienter i Nord-Trøndelag demens

- Av disse hadde rundt $75 \%$ ett eller flere klinisk signifikante nevropsykiatriske symptomer i tillegg

- De nevropsykiatriske symptomene omfattet psykose, agitasjon, apati og affektive symptomer

- Funnene samsvarer med funn fra tidligere studier i andre fylker 
depresjonssymptomer, fungering i dagliglivet, demensgrad og somatisk sykdom.

Kartleggingsskjemaet Klinisk demensvurdering angir alvorlighetsgrad av demenssykdommen ved hjelp av seks kategorier (12). Hver kategori skåres fra 0 til 3, der $0=$ ingen demens, $0,5=$ mulig demens og 1 , 2 eller 3 betegner henholdsvis mild, moderat og alvorlig demens. Totalskåren utledes etter en algoritme som gir ekstra vekt til sviktende hukommelse.

Nevropsykiatrisk intervjuguide er et skjema for kartlegging av 12 nevropsykiatriske symptomer ved demens (13). For hvert symptom skåres frekvens og alvorlighetsgrad de siste fire uker, som multipliseres til en symptomskår (0-12 poeng), der høyere skår betyr alvorligere symptom. En symptomskår på 4 eller høyere er definert som klinisk signifikant (14). Den norske versjonen av Nevropsykiatrisk intervjuguide er testet for reliabilitet og validitet (15). Forekomsten av nevropsykiatriske symptomer ble sammenliknet med forekomsten $\mathrm{i}$ en tidligere studie i fire andre norske fylker i 2004-05 (7).

Lawton's physical self-maintenance scale måler pasientens evne til å klare seks dagligdagse aktiviteter selv (activity of daily life; ADL). Totalskår er 5-30, og høyere skår betyr dårligere funksjonsnivå (16). General medical health rating scale er en firepunktsskala for skåring av somatisk sykdomsgrad. Skårene ble dikotomisert til alvorlig somatisk sykdom (de to høyeste skårene) og god somatisk helse (de to laveste) (17).

\section{Etikk og personvern}

Avhengig av pasientens samtykkekompetanse ga pasienten selv eller nærmeste pårørende samtykke til deltakelse i studien. Studien var godkjent av regional komité for medisinsk og helsefaglig forskningsetikk i Midt-Norge.

\section{Statistisk analyse}

Analysene ble gjort med Statistical Product and Service Solutions (SPSS), versjon 18.0. Data ble beskrevet med frekvensfordeling for kategoriske variabler, gjennomsnitt og standardavvik for kontinuerlige variabler med normal distribusjon og median og interkvartilbredde (IQR) for skjevfordelte kontinuerlige variabler. Kontinuerlige data ble sammenliknet med t-test dersom de var normalfordelte eller med Mann-Whitneys U-test dersom de ikke var normalfordelte, mens kategoriske variabler ble sammenliknet med krysstabeller.

Vi gjorde en eksplorerende faktoranalyse, der ekstraksjon av faktorer ble bestemt av egenverdi $>1$ og inspeksjon av mønsteret som dannes av egenverdiene (scree-plot). Kriterier for adekvat tilpasning av faktoranalysen var signifikant funn ved Bartlett's test of sphericity og Kayser-Meyer-Olkins (KMO) mål for adekvat utvalgsstørrelse $>0,7$. Faktoranalysen ble gjort med oblik (direkte oblimin) rotasjon.

Tabell 1 Demografiske data og funn for 704 sykehjemspasienter Nord-Trøndelag undersøk i 2010-11 for demens ved bruk av kartleggingsverktøyet Klinisk demensvurdering. P-verdier angir forskjeller mellom pasienter med og pasienter uten demens. Tallene er oppgitt i antall [\%] dersom ikke annet er angitt

\begin{tabular}{|c|c|c|c|c|}
\hline & $\begin{array}{c}\text { Alle } \\
(\mathrm{N}=704)\end{array}$ & $\begin{array}{l}\text { Med demens } \\
(n=575)\end{array}$ & $\begin{array}{l}\text { Uten demens } \\
\quad(n=129)\end{array}$ & P-verdi \\
\hline Alder i år, gjennomsnitt (standardavvik) & $84,5(8,3)$ & $84,7(8,1)$ & $84,1(8,9)$ & \\
\hline ADL-skår, gjennomsnitt (standardavvik) & $17,9(5,7)$ & $18,8(5,4)$ & $13,5(4,7)$ & $<0,001^{1}$ \\
\hline $\begin{array}{l}\text { Antall medikamenter, } \\
\text { gjennomsnitt (standardavvik) }\end{array}$ & $6,7(3,6)$ & $6,3(3,3)$ & $8,3(4,5)$ & $<0,001^{1}$ \\
\hline Kvinner & $500(71)$ & 409 (71) & $91(71)$ & \\
\hline \multicolumn{5}{|l|}{ Sivilstand } \\
\hline Ugift & $67(10)$ & $50(9)$ & $17(13)$ & \\
\hline Gift & 170 (25) & $146(26)$ & $24(19)$ & \\
\hline Enke/enkemann & $428(62)$ & $347(62)$ & $81(63)$ & \\
\hline Skilt/separert & $26(4)$ & $21(4)$ & $5(4)$ & \\
\hline Alvorlig somatisk sykdom & $359(50)$ & 302 (53) & 47 (37) & $0,001^{2}$ \\
\hline Regelmessig bruk av legemidler & $659(94)$ & $540(94)$ & 119 (92) & \\
\hline Regelmessig bruk av psykofarmaka & 440 (63) & 355 (62) & $85(66)$ & \\
\hline \multicolumn{5}{|l|}{ Klinisk demensvurdering (skjema) } \\
\hline 0 & & & $33(26)$ & \\
\hline 0,5 & & & $96(74)$ & \\
\hline 1 & & 125 (22) & & \\
\hline 2 & & 164 (29) & & \\
\hline 3 & & 286 (50) & & \\
\hline
\end{tabular}

Tabell 2 Prinsipal komponentekstraksjonanalyse (PCA) av Nevropsykiatrisk intervjuguide for 704 sykehjemspasienter i Nord-Trøndelag undersøkt i 2010-11 for demens og nevropsykiatriske symptomer. Uthevede tall angir symptomer med faktorladning (factor loading) over 0,5

\begin{tabular}{|c|c|c|c|c|}
\hline & $\begin{array}{l}\text { Faktor } 1 \\
\text { Agitasjon }\end{array}$ & $\begin{array}{c}\text { Faktor } 2 \\
\text { Apati }\end{array}$ & $\begin{array}{l}\text { Faktor } 3 \\
\text { Psykose }\end{array}$ & $\begin{array}{c}\text { Faktor } 4 \\
\text { Affektive symptomer }\end{array}$ \\
\hline Vrangforestilling & 0,08 & $-0,16$ & 0,64 & $-0,37$ \\
\hline Hallusinasjon & $-0,01$ & $-0,17$ & 0,73 & $-0,16$ \\
\hline Agitasjon & 0,67 & 0,14 & 0,20 & $-0,12$ \\
\hline Depresjon & 0,13 & 0,20 & $-0,14$ & $-0,80$ \\
\hline Angst & 0,22 & 0,00 & 0,20 & $-0,74$ \\
\hline Oppstemthet & 0,64 & $-0,16$ & 0,17 & $-0,03$ \\
\hline Apati & $-0,04$ & 0,72 & $-0,05$ & $-0,21$ \\
\hline Hemningsløshet & 0,80 & 0,21 & 0,10 & 0,08 \\
\hline Irritabilitet & 0,70 & 0,11 & 0,15 & $-0,15$ \\
\hline Motorisk uro & $-0,06$ & 0,34 & 0,68 & 0,10 \\
\hline Nattlig uro & 0,24 & 0,02 & 0,53 & 0,14 \\
\hline Appetitt & 0,07 & 0,74 & 0,00 & $-0,04$ \\
\hline
\end{tabular}

\section{Resultater}

Demografiske variabler for alle pasientene fremgår av tabell 1. Bedømt med kartleggingsverktøyet Klinisk demensvurdering hadde 575 pasienter $(82 \%)$ demens. Disse hadde oftere alvorlig somatisk sykdom og hadde større funksjonssvikt, men signifikant lavere medikamentbruk enn pasientene uten demens (tab 1).

Andelen pasienter som hadde klinisk signi- fikante nevropsykiatriske symptomer er vist $\mathrm{i}$ figur $1 \mathrm{og}$ er sammenliknet med tilsvarende data $i$ en norsk sykehjemsstudie fra 2004-05 (7). Av pasientene med demens hadde $75 \%$ ett eller flere klinisk signifikante nevropsykiatriske symptomer. De tre hyppigst forekommende symptomene var vrangforestillinger, apati og irritabilitet. Bortsett fra vrangforestillinger, som var mer vanlig i vår studie $(p=0,033)$, var det ingen forskjell i forekomst 


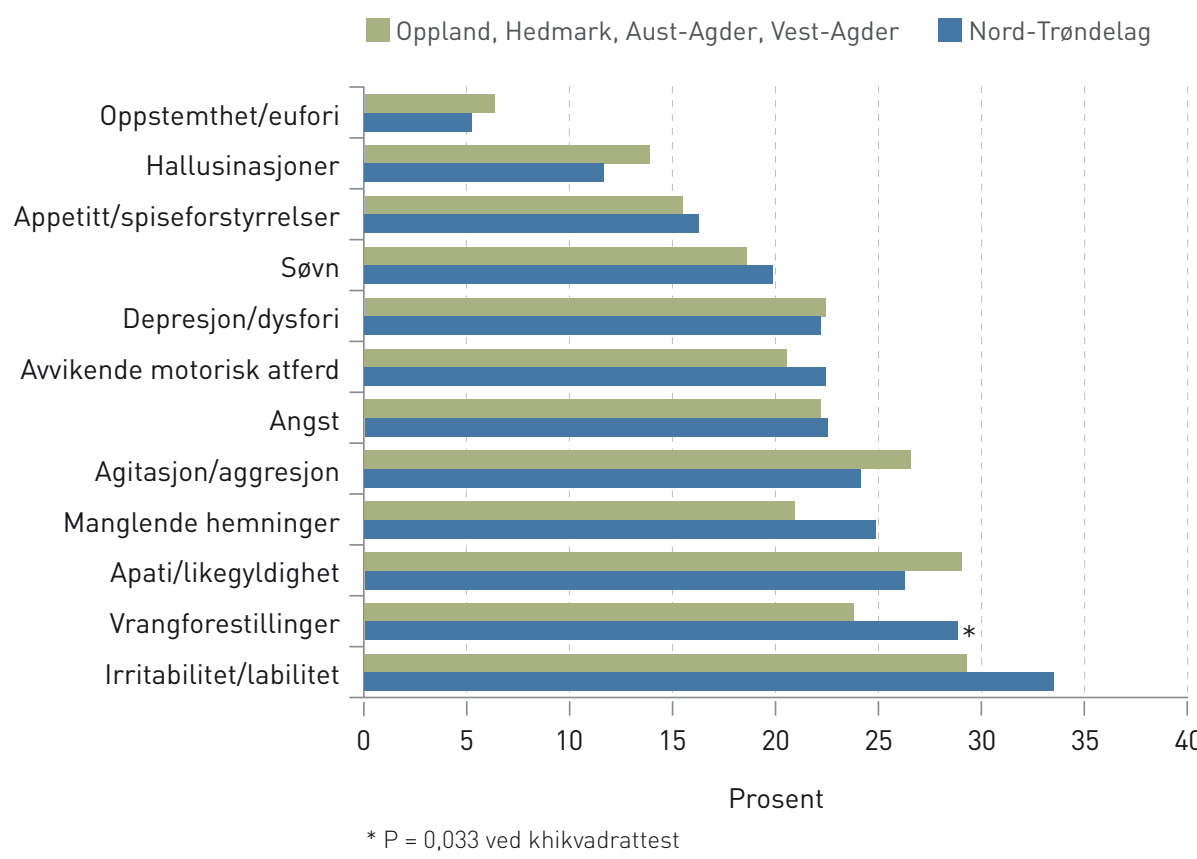

Figur 1 Prevalens av nevropsykiatriske symptomer kartlagt med nevropsykiatrisk intervjuguide i to kohorter i henholdsvis Nord-Trøndelag i 2010-11 (n = 704) og i Oppland, Hedmark, Aust-Agder og Vest-Agder i $2004-05$ ( $n=933)(7)$

av enkeltsymptomer mellom denne studien og studien fra i $2004-05$.

Ved faktoranalyse av Nevropsykiatrisk intervjuguide, gjennomført som en prinsipal komponentekstraksjonanalyse av undersymptomene i intervjuguiden, ble fire faktorer identifisert ( $\operatorname{tab} 2$ ). For modellen var Bartlett's test of sphericity signifikant $(\mathrm{p}<0,001)$ og Kayser-Meyer-Olkins mål for adekvat utvalgsstørrelse 0,82 , dvs. over 0,7 , som er vanlig i tilsvarende studier.

Agitasjon (faktor 1) besto av agitasjon, oppstemthet, manglende hemninger og irritabilitet. Apati (faktor 2) besto av symptomene apati og appetitt. Psykose (faktor 3) besto av vrangforestillinger, hallusinasjoner, motorisk uro og nattlig uro. Affektive symptomer (faktor 4) besto av depresjon og angst. Vi beregnet også korrelasjoner mellom faktorene. Høyest positiv korrelasjon var det mellom agitasjon og psykose, mens agitasjon og affektive symptomer hadde høyest negativ korrelasjon.

\section{Diskusjon}

Denne studien viser at det er en høy forekomst av demens blant sykehjemspasienter i Nord-Trøndelag. Mange av pasientene med demens hadde i tillegg ett eller flere nevropsykiatriske symptomer. Forekomsten av demens og nevropsykiatriske symptomer var sammenliknbar med forekomsten i en tidligere studie fra fire norske fylker i 2004-05 (7).

Det var ingen statistisk signifikante forskjeller mellom de to studiene, med unntak av forekomsten av vrangforestillinger. Det er mulig at forekomsten av nevropsykiatriske symptomer varierer mer mellom avdelinger på ett sykehjem eller mellom syke- hjem i samme fylke enn mellom et utvalg av pasienter i forskjellige fylker, men det har vi ikke analysert. Den statistisk signifikante forskjellen i forekomst av vrangforestillinger mellom utvalgene er uansett liten og bør ikke tillegges mye vekt. Likheten i forekomst av nevropsykiatriske symptomer mellom studiene kan tyde på at hyppigheten av slike symptomer er uavhengig av ytre faktorer som organisering av sykehjemstjenesten og medikamentbruken, men mer et uttrykk for demenssykdommen i seg selv.

Faktoranalysen av nevropsykiatriske symptomer i vår studie identifiserte fire faktorer: psykose, agitasjon, affektive symptomer og apati. I en annen norsk longitudinell sykehjemsstudie fant man at de samme fire faktorene var de mest stabile (11). Faktorstabiliteten mellom studier på tvers av geografisk område og tidsperiode for datainnsamling tyder på at det finnes undergrupper av pasienter med demens med gjenkjennbare mønstre av nevropsykiatriske symptomer. Dette støttes også av internasjonale studier, der det er gjort tilsvarende funn (18). Inndelingen av nevropsykiatriske symptomer i slike faktorer er nyttig som utfallsmål i studier og ved evaluering av symptomårsaker og effekt av medikamentell behandling.

Studiens styrke er bl.a. et stort antall pasienter fordelt på mange sykehjem. Kohortens størrelse tilsier at den er representativ for sykehjemspasienter i Nord-Trøndelag. Bruken av standardiserte kartleggingsskjemaer som er validert på norsk og som er mye brukt $\mathrm{i}$ internasjonal forskning, er også viktig. Antallet datainnsamlere var dessuten lavt, og de hadde alle fătt opplæring i kartleggingsverktøyene før datainnsamlingen startet.

Én begrensning er mangelen på klinisk verifisert demensdiagnose, men tidligere studier har vist at demens diagnostisert ved hjelp av klinisk demensvurdering er et valid substitutt for diagnostisering ved klinisk undersøkelse $(19,20)$. En annen begrensning er at relativt mange pasienter sa nei til deltakelse eller ble ekskludert av andre årsaker.

\section{Konklusjon}

Forekomsten av demens blant sykehjemspasienter i Nord-Trøndelag er høy, og mange av pasientene med demens har ett eller flere klinisk signifikante nevropsykiatriske symptomer i tillegg, hvorav vrangforestillinger, apati og irritabilitet er hyppigst. Den høye forekomsten av demens og nevropsykiatriske symptomer har betydning for klinisk praksis, drift og planlegging av sykehjem og viser at helsepersonell i sykehjem må ha god kompetanse om demens og nevropsykiatriske symptomer.

Studien er en delstudie i prosjektet Helse og hukommelse i Nord-Trøndelag, som er et samarbeidsprosjekt mellom HUNT, Norges teknisknaturvitenskapelige universitet, Folkehelseinstituttet, Helse Midt-Norge RHF, Helse Nord-Trøndelag HF, Fylkesmannen i Nord-Trøndelag, Kommunenes sentralforbund i Nord-Trøndelag og Alderspsykiatrisk forskningssenter, Sykehuset Innlandet.

\section{Sverre Bergh (f. 1973)}

er postdoktorstipendiat og lege i spesialisering ved Alderspsykiatrisk forskningssenter, Sykehuset Innlandet. Han er også tilknyttet Nasjonalt kompetansesenter for aldring og helse. Forfatter har fylt ut ICMJE-skjemaet og oppgir ingen interessekonflikter.

\section{Jostein Holmen (f. 1947)}

er professor i anvendt samfunnsmedisin og tidligere leder for Helseundersøkelsen i NordTrøndelag (HUNT) og HUNT forskningssenter. Norges teknisk-naturvitenskapelige universitet Forfatter har fylt ut ICMJE-skjemaet og oppgir ingen interessekonflikter.

\section{Ingvild Saltvedt (f. 1960)}

er spesialist i indremedisin og i geriatri, overlege ved Avdeling for geriatri ved St. Olavs hospital og førsteamanuensis ved Institutt for nevromedisin, Norges teknisk-naturvitenskapelige universitet.

Forfatter har fylt ut ICMJE-skjemaet og oppgir følgende interessekonflikter: Har fått støtte til kongressreiser/faglige møter fra Mundipharma, Novartis og Lundbeck.

\section{Kristian Tambs (f. 1951)}

er cand.psychol., dr.philos. og forskningssjef ved Divisjon for psykisk helse, Nasjonalt folkehelseinstitutt.

Forfatter har fylt ut ICMJE-skjemaet og oppgir ingen interessekonflikter. 


\section{Geir Selbæk (f. 1963)}

er spesialist i psykiatri og har en ph.d.-grad innen geriatri. Han er forskningsleder ved Alderspsykiatrisk forskningssenter, Sykehuset Innlandet, og er tilknyttet Akershus universitetssykehus og Nasjonalt kompetansesenter for aldring og helse.

Forfatter har fylt ut ICMJE-skjemaet og oppgir følgende interessekonflikter: Har fått foredragshonorar fra Lundbeck og Novartis.

\section{Litteratur}

1. Engedal K, Haugen PK. Demens, fakta og utfordringer. Oslo: Nasjonalt kompetansesenter for aldersdemens, 2004

2. Sourial R, McCusker J, Cole M et al. Agitation in demented patients in an acute care hospital: prevalence, disruptiveness, and staff burden. Int Psychogeriatr 2001; 13: 183-97.

3. Kirkevold O, Laake K, Engedal K. Use of constraints and surveillance in Norwegian wards for the elderly. Int J Geriatr Psychiatry 2003; 18 . 491-7.

4. Bartels SJ, Horn SD, Smout RJ et al. Agitation and depression in frail nursing home elderly patients with dementia: treatment characteristics and service use. Am J Geriatr Psychiatry 2003: 11: 231-8.

5. Rongve A, Auning E, Ehrt U et al. Psykose ved Par- kinsons sykdom. Tidsskr Nor Legeforen 2012: 132 $155-8$

6. Bergh S, Engedal K, Røen I et al. The course of neuropsychiatric symptoms in patients with dementia in Norwegian nursing homes. Int Psychogeriatr 2011; 23: 1231-9.

7. Selbæk G, Kirkevold O, Engedal K. The prevalence of psychiatric symptoms and behavioural disturbances and the use of psychotropic drugs in Norwegian nursing homes. Int J Geriatr Psychiatry 2007: 22: 843-9.

8. Zuidema SU, Derksen E, Verhey FR et al. Prevalence of neuropsychiatric symptoms in a large sample of Dutch nursing home patients with dementia. Int J Geriatr Psychiatry 2007; 22: 632-8.

9. Wetzels RB, Zuidema SU, de Jonghe JF et al. Course of neuropsychiatric symptoms in residents with dementia in nursing homes over 2-year period. Am J Geriatr Psychiatry 2010: 18: 1054-65.

10. Ballard CG, Margallo-Lana M, Fossey J et al. A 1-year follow-up study of behavioral and psychological symptoms in dementia among people in care environments. J Clin Psychiatry 2001; 62: 631-6.

11. Selbæk G, Engedal K. Stability of the factor structure of the Neuropsychiatric Inventory in a 31 -month follow-up study of a large sample of nursing-home patients with dementia. Int Psychogeriatr 2012; 24: 62-73.

12. Berg L. Clinical Dementia Rating (CDR). Psychopharmacol Bull 1988; 24: 637-9.

13. Cummings JL, Mega M, Gray K et al. The Neuropsychiatric Inventory: comprehensive assessment of psychopathology in dementia. Neurology 1994: 44: $2308-14$.
14. Steinberg M, Tschanz JT, Corcoran C et al. The persistence of neuropsychiatric symptoms in dementia: the Cache County Study. Int J Geriat Psychiatry 2004; 19: 19-26.

15. Selbæk G, Kirkevold O, Sommer $\mathrm{OH}$ et al. The reliability and validity of the Norwegian version of the Neuropsychiatric Inventory, nursing home version (NPI-NH). Int Psychogeriatr 2008; 20: 375-82.

16. Lawton MP. Brody EM. Assessment of older people: self-maintaining and instrumental activities of daily living. Gerontologist 1969; 9: 179-86.

17. Lyketsos CG, Galik E, Steele C et al. The General Medical Health Rating: a bedside global rating of medical comorbidity in patients with dementia. J Am Geriatr Soc 1999; 47: 487-91.

18. Aalten $P$, de Vugt ME, Lousberg R et al. Behavioral problems in dementia: a factor analysis of the neuropsychiatric inventory. Dement Geriatr Cogn Disord 2003; 15: 99-105.

19. Engedal K. The prevalence of dementia in a sample of elderly Norwegians. Int J Geriatr Psychiatry 1993; 8: 565-70

20. Nygaard HA, Ruths S. Missing the diagnosis: senile dementia in patients admitted to nursing homes. Scand J Prim Health Care 2003; 21 $148-52$.

Mottatt 20.2. 2012, første revisjon innsendt 9.5. 2012, godkjent 21.6. 2012. Medisinsk redaktør Petter Gjersvik. 